\title{
EVAPORADOR MODELO ROBERT
}

\section{ARTIGO ORIGINAL}

SANTOS, Alexsander Saves dos ${ }^{1}$

SILVA, Emily Bueno da ${ }^{2}$

OLIVEIRA, Deborah Ribeiro ${ }^{3}$

VALEIRO, Alex Alves 4

CABRERA, Alonso Mendes 5

OLIVEIRA, Felipe Arruda de ${ }^{6}$

VICENTE, Ariane Parra ${ }^{7}$

Alexsander Saves dos Santos. Et al. Evaporador modelo Robert. Revista Científica Multidisciplinar Núcleo do Conhecimento. Ano 04, Ed. 06, Vol. 03, pp. 47-61. Junho de 2019. ISSN: 2448-0959.

\footnotetext{
${ }^{1}$ Graduação em Física pelo Centro Universitário de Votuporanga (2006)/ Graduação em Pedagogia pela faculdade de Aldeia de Carapicuíba(2016)/ Pós Graduação em Fundamento a Pratica de Ensino do Professor de Matemática pela Universidade Estadual Paulista Júlio de Mesquita Filho/ UNESP/ Campus de Ilha Solteira (SP) (2010)/ Mestrado em Ciências Ambientais pela Universidade Brasil (2018).

2 Estudante de Engenharia Química.

${ }^{3}$ Estudante de Engenharia Química.

4 Estudante de Engenharia Química.

${ }^{5}$ Graduado em Química e estudante de Engenharia Química.

${ }^{6}$ Estudante de Engenharia Química.

${ }^{7}$ Estudante de Engenharia Química.
} 


\section{RESUMO}

A evaporação é uma das operações unitárias mais utilizadas em processos solventes em forma de vapor. O evaporador tipo Robert's é o mais utilizado nas indústrias açucareiras devido a sua área de aquecimento. Assim este projeto teve o objetivo de confeccionar um equipamento de evaporação modelo Robert's, retirando toda a água presente no caldo através da evaporação, promovendo a concentração para obtenção do xarope.

Palavras-chaves: evaporador, Modelo Robert, operações unitárias.

\section{INTRODUÇÃO}

A evaporação é a operação unitária que consiste em concentrar uma solução pela ebulição do solvente. Normalmente, suspende-se o processo de concentração antes de o soluto começar a precipitar da solução (FOUST et al, 1982).

Na sua forma básica, portanto, um evaporador é constituído por um trocador de calor, capaz de levar a solução à fervura, e de um dispositivo para separar a fase vapor do líquido em ebulição (FOUST et al, 1982).

De acordo com Araújo (2012), a evaporação consiste no processo de remoção de solventes, na forma de vapor, realizada em um evaporador, cuja principal função resume-se em concentrar um soluto não volátil a partir da remoção de um solvente volátil.

Segundo Mccabe et. al. (1991), evaporadores são constituídos de um tanque, em que se encontra a solução a ser concentrada, com uma entrada, na qual acontece a injeção de solução de forma controlada, e saída, para a solução concentrada e para o solvente volatilizado. Estes possuem uma área de troca térmica composta por um trocador de calor, que fornece energia para a evaporação do solvente. 
Conforme reportado por Mccabe et. al. (1991), o solvente é a água na maioria dos evaporadores. O processo de evaporação acontece de forma a retirar parte do solvente da solução na forma de vapor, a fim de obter um produto concentrado.

Segundo Araújo (2012), os evaporadores, em sua totalidade, possuem uma superfície térmica, cuja função é transferir calor para a solução e um compartimento, voltado a separar o vapor produzido da solução alimentada. Tal compartimento, também denominado de espaço vapor, visa impedir o arraste da solução ocasionada pela geração do vapor.

Em relação à forma de separação do vapor, é possível classificar os evaporadores em três categorias:

- Evaporadores de circulação natural;

- Evaporadores de circulação forçada;

- Evaporadores de película.

Conforme Araújo (2012), os evaporadores de circulação natural podem aparecer de duas formas diferentes, tubos horizontais e tubos verticais.

Segundo Foust et. al. (2011), nos evaporadores de tubos horizontais, a solução entra em ebulição no exterior dos tubos, sendo que nesses ocorre a condensação do vapor de água.

Os tubos interferem na circulação natural da solução, com isso a agitação diminui. Nesse caso o coeficiente global de transferência de calor é menor que nos outros tipos de evaporadores, principalmente quando as soluções são viscosas.

Ainda de acordo com Foust et. al. (2011), nos evaporadores de tubos verticais podem aparecer dois tipos, os de cesta e os de tubos curtos ou calandra. Nesse caso a solução a ser concentrada entra em ebulição no interior dos tubos verticais, e o fluido de aquecimento fica em uma câmara de vapor na qual os tubos passam. 
Os tubos verticais são vantajosos à medida que se leva em consideração as desvantagens operacionais dos evaporadores de tubos horizontais.

De acordo com Araújo (2012), o evaporador tipo calandra normalmente é composto de tubos de aço ou de latão, em que os diâmetros mais comuns são de 32, 35, 45 e $50 \mathrm{~mm}$ e com espessura de parede de $1,5 \mathrm{~mm}$ podendo chegar até $2,5 \mathrm{~mm}$. Já o comprimento desses tubos varia entre $2,25 \mathrm{~m}$ a $4 \mathrm{~m}$, uma vez que existe uma relação entre o diâmetro e o comprimento dos tubos.

Como reportado por Araújo (2012), os evaporadores de circulação forçada, consistem em equipamentos que possuem uma bomba instalada para promover o fluxo ascendente da solução, pois com o aumento da velocidade de escoamento dessa solução na região interna dos tubos, ocorre um aumento do coeficiente de transferência de calor por convecção, que nesse caso, é utilizado em operações de cristalização ou em lamas viscosas.

Segundo Foust et. al. (2011), nesse tipo de sistema o líquido evaporante é bombeado através de um trocador de calor onde o meio calefator circunda os tubos portadores da solução.

A perda de pressão e a pressão hidrostática, combinadas, são muitas vezes bastante grandes para impedir a ebulição da solução nos tubos trocadores, e por isso o vapor gerado forma-se instantaneamente quando o líquido entra na câmara de vaporização. (FOUST et. al., 2011)

Nos evaporadores, o coeficiente de transferência de calor depende da velocidade de circulação e da variação de temperatura global, da temperatura de ebulição e das propriedades do sistema (Foust et al., 2011)

Segundo Walas (1990), os evaporadores verticais de tubo longo com circulação natural ou forçada são mais comumente utilizados, quando comparado aos outros tipos. 
De acordo com Foust et. al. (2011), os evaporadores verticais de tubos longos podem atingir vazões elevadas da solução devido a convecção natural. A mistura de líquido e vapor sai através da parte superior dos tubos e projeta-se contra uma chicana. $A$ velocidade do mosto evaporado é alta o suficiente para que a chicana atue como um eliminador de espuma.

Mccabe et. al. (1991) reporta que os evaporadores de película podem ser classificados, de acordo com o fluxo: ascendente e descendente. No caso do evaporador com película ascendente, o líquido e o vapor ascendem do fundo para a parte superior do evaporador por dentro do tubo em consequência da ebulição e o líquido separado retorna ao fundo do recipiente por gravidade.

A alimentação, que está diluída, entra no sistema com temperatura próxima a do 18 ambiente e se mistura com o líquido que é retornado. Esse tipo de evaporador é muito eficaz para processos que envolvam líquidos que tendem a formar espuma.

De acordo com Mccabe et. al. (1991), os evaporadores de película descendente são usados para concentrar materiais de alta sensibilidade em relação ao calor, nos quais necessitam de um tempo mínimo de exposição ao aquecimento. Normalmente, esse processo é atingido com um sistema de apenas um efeito, com a solução a ser concentrada entrando pela parte superior, e se deslocando para a parte inferior através dos tubos aquecidos juntamente com vapor de água.

O vapor é arrastado para o fundo do equipamento junto com o concentrado, que será retirado pela parte inferior do evaporador.

Conforme abordado por Araújo (2012), há também evaporadores de película agitada, que são formados por um tubo com aquecimento e com rotor interno, em que as suas laminas quase chegam a parede interna do tubo, sendo essa aquecida, já que essa parte aquecida corresponde a $2 / 3$ de todo o comprimento total, e a parte sem aquecimento possui diâmetro maior. 
A alimentação é realizada somente pelo setor superior do evaporador, com o rotor atuando diretamente nesse processo, jogando toda a alimentação nas paredes aquecidas, na qual escorre e ocorre a troca de calor. Esse mesmo rotor evita que depósitos se formem no interior do tubo e que a película fique espessa. 3.2.4.

Evaporadores de placas ainda de acordo com Araújo (2012) podem ser estudados também os evaporadores de placas, que são parecidos com os trocadores de calor que utilizam placas, mas possuem uma grande passagem para o vapor formado.

Nesses evaporadores, o aumento da velocidade de escoamento colabora com a redução das incrustações no sistema, pois o volume que fica retido no interior do evaporador é pequeno, quando comparado a outros equipamentos.

Segundo Araújo (2012), há mais um tipo de evaporador, denominado de híbrido. Esta denominação acontece pelo fato de que este evaporador possui placas e fluxo descendente, sendo constituído pela união de um evaporador de placas e um evaporador de feixe tubular de fluxo descendente.

Nesse evaporador a calandra é formada por um conjunto de placas soldadas e ainda, o fabricante apresenta a possibilidade de modificar um evaporador tipo Roberts para um tipo híbrido. 19 3.2.5.

Conforme reportado por Foust et. al. (2011), nas operações que envolvem evaporação, a representação principal do custo do processo está relacionada ao vapor d'água consumido. Portanto, métodos de economia de energia, exemplificado pela razão entre a massa de vapor produzida e a massa de vapor consumida ou a redução de consumo de vapor, são geralmente aplicados.

Uma forma de se obter essa redução do consumo de vapor é a reutilização do vapor gerado no sistema.

De acordo com Araújo (2012), os evaporadores de múltiplos efeitos são constituídos de forma que dois ou mais evaporadores idênticos sejam colocados em série, e que 
o vapor produzido no efeito anterior seja utilizado no aquecimento do evaporador seguinte, o vapor gerado no ultimo efeito vai para um condensador, e a solução produzida no efeito anterior pode ser concentrada ainda mais no efeito seguinte.

A evaporação é um processo com um intenso gasto de energia em vários processos industriais como, por exemplo, na indústria de papel e celulose, de açúcar, de leite e de café - alimentos em geral (BHARGAVA et al., 2010).

A evaporação difere da desidratação, pois o produto tratado por este processo permanece sempre no estado líquido, também difere da destilação, já que o vapor produzido não contém concentrações diferentes, como na destilação.

Em que se concentra uma solução pela ebulição do solvente. Nos casos normais, suspende-se o processo concentrante antes de o soluto principiar a precipitasse da solução.

Na sua forma básica, portanto, um evaporador é constituído por um trocador de calor, capaz de levar a solução à fervura, e de um dispositivo para separar a fase vapor do líquido em ebulição. Na sua forma mais simples pode ser um tabuleiro contendo o líquido e o caldo sobre uma chapa quente.

A superfície da chapa quente é um trocador de calor simplificado, e a separação do vapor se consegue graças à grande área disponível para escoar o vapor, com o que se tem uma pequena velocidade de escoamento.

Segundo Rogério et al. (2013) O evaporador tipo Robert é o mais utilizado nas indústrias açucareiras devido a sua área de aquecimento. Diante desse aspecto, as indústrias não visam somente o produto final, e sim um subproduto, o bagaço.

A evaporação utilizada no processamento de alimentos em grandes volumes tem preferência por evaporador de passagem rápida devido ao tempo de exposição da solução, não prejudicando as características da solução. 
A evaporação, não resume apenas na concentração de uma solução propriamente dita, mas abrange um leque maior nas indústrias, sendo responsável pelo balanço energético de uma indústria obtendo economia de energia através dos vapores, condensados gerados e transferência de calor envolvido neste processo. Modelos e arranjos matemáticos de evaporadores existem em diversos segmentos industriais, e para cada tipo de segmento é levado em consideração o ponto de ebulição preservando o aroma, extrato e propriedades físico-químicas do fluido a ser concentrado.

\section{OBJETIVO}

Confeccionar um equipamento de evaporação modelo Robert.

Retirar água presente no caldo através da evaporação, promovendo a concentração para obtenção do xarope.

Aplicar os conhecimentos de operações unitárias obtidos no curso de Engenharia Química.

\section{METODOLOGIA}

Em primeira instância foi necessário escolher um projeto de evaporador de escala industrial, esse por sua vez foi elaborado pela empresa SUCRANA Assessoria e Tecnologia S/S Ltda. sob a solicitação da Usina Colombo S/S da unidade da cidade de Santa Albertina com o princípio de servir como base para a construção do projeto em questão. Estabeleceu-se que o projeto do evaporador corresponderia à 2,8\% do evaporador industrial.

Feito isso, observou que para fornecer calor em forma de vapor ao evaporador, era primordial ter uma caldeira ou gerador de vapor acoplado ao sistema. Iniciou-se então a construção, compras e montagem das peças a serem utilizadas. 
O gerador de vapor ou caldeira é constituído por uma fornalha ou forno Figura 1, situada abaixo do corpo cilíndrico Figura 2. Entra inicialmente em contato com a base inferior do cilindro, de modo a aquecer a parte inferior da caldeira e produzir calor Figura 3; o calor gerado é transferido para a água que deve estar entre $110 \cong$ à $130^{\circ}$ transformando-a em vapor, processo de ebulição. Isto produz vapor saturado a uma taxa que pode variar de acordo com a pressão $(300 \mathrm{~g}$ à $500 \mathrm{~g})$ da água fervente.

Para garantir a segurança instalou-se um manômetro (pressão), um termômetro (temperatura), um registro para regular a saída de vapor e sendo feita de aço inox 304 devido a sua boa resistência à corrosão e a oxidação é bastante utilizado em indústrias.

Figura 1: Fonte de calor utilizada - fogareiro.

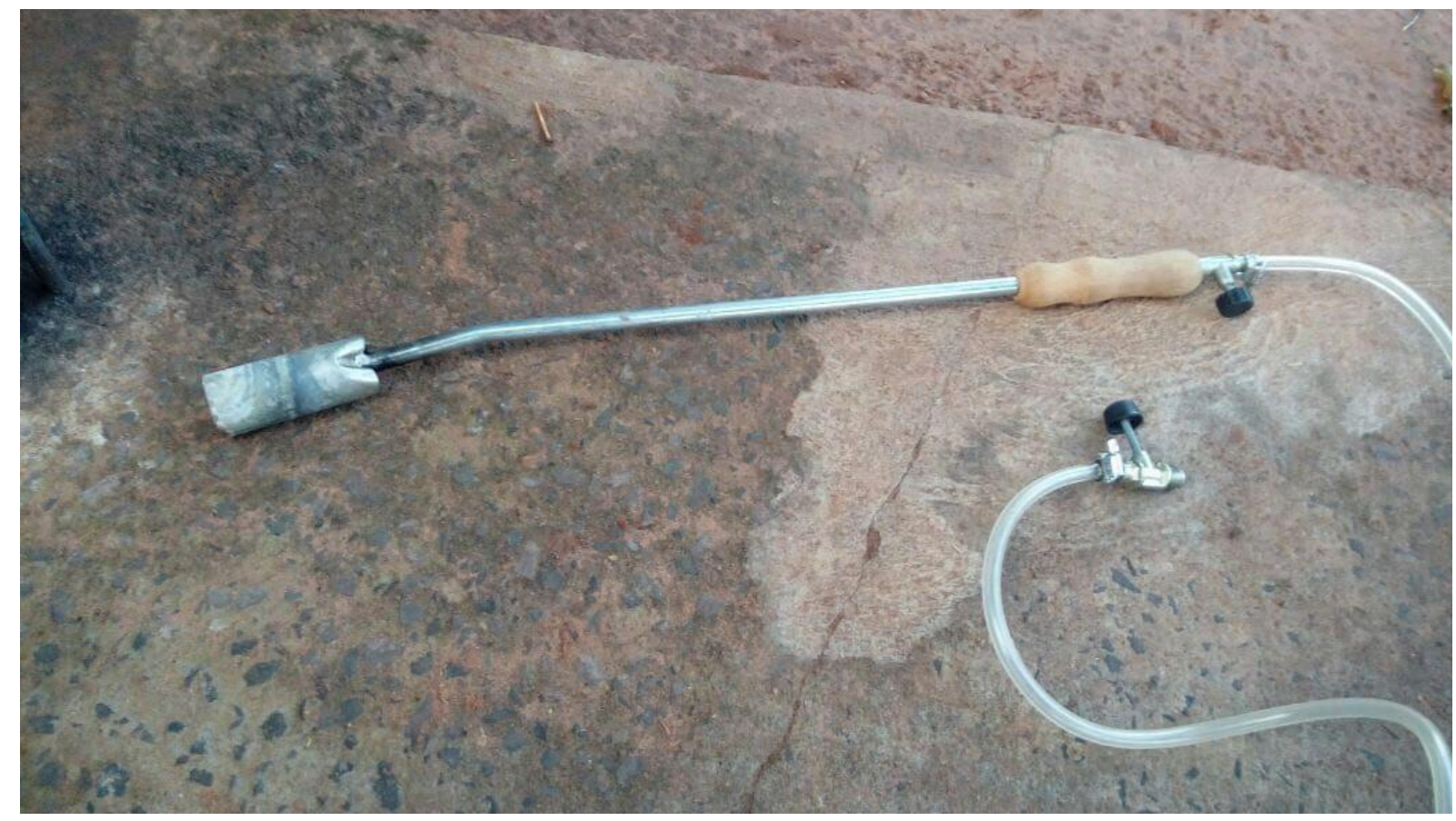

Fonte: autor.

Disponível em: https://www.nucleodoconhecimento.com.br/engenharia-quimica/evaporadormodelo-robert 
Figura 2: Montagem inicial da caldeira.

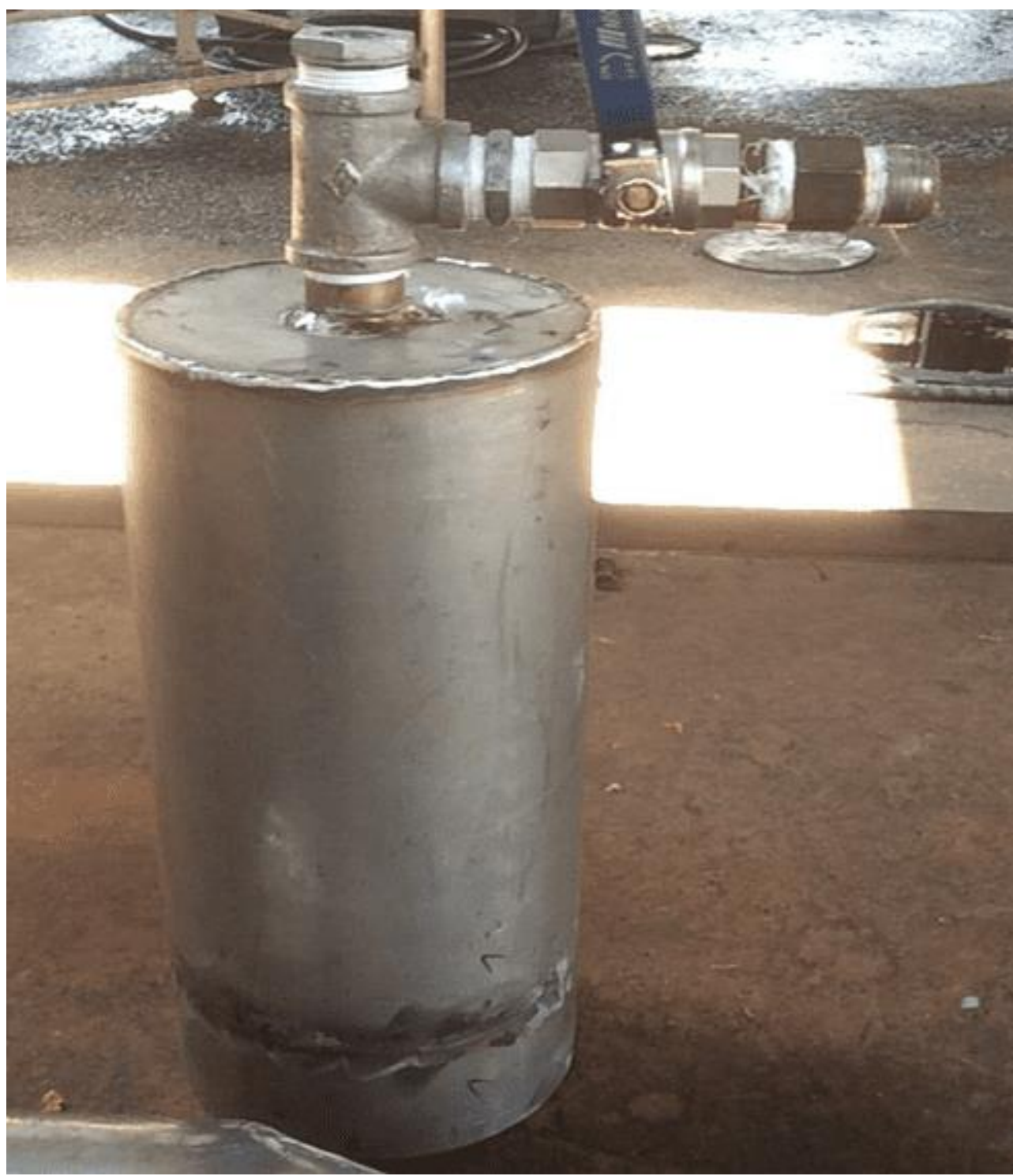

Fonte: autor.

RC: 31674

Disponível em: https://www.nucleodoconhecimento.com.br/engenharia-quimica/evaporadormodelo-robert 
Figura 3: Demonstração da caldeira.

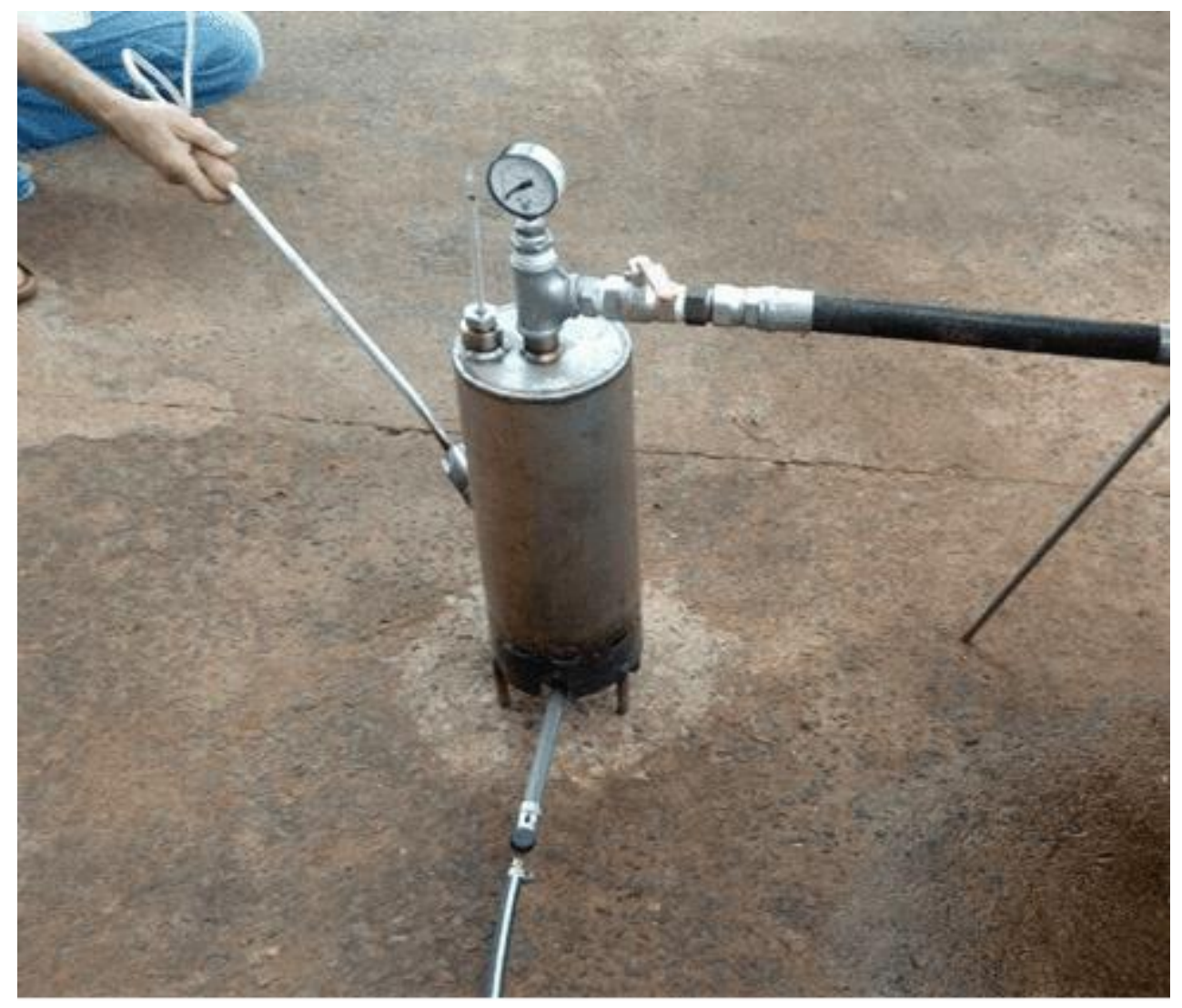

Fonte: autor.

Para construir o evaporador foram estipulados com base no projeto industrial quantos tubos seriam necessários para construir a calandra, principal parte do evaporador. Foram feitos 64 tubos de cobre 3/8" Figura 4, 2 espelhos 3/16" Figura 5, chapa aço carbono 3/8" e 10mm de espessura Figura 6, esse por sua vez utilizaram 8 parafusos para fixar e servir de encaixe entre parte inferior e superior (flange) e um tubo de 1" com 6 rasgo de 1/4" Figura 7, se fez necessário mandrilar os tubos e solda-lós.

Acima do espelho superior está localizado a saída de caldo que consiste em coletar o caldo com maior concentração tendo um registro de 1/2" para regular a quantidade de saída, por sua vez abaixo no espelho inferior está localizado a entrada do caldo (funil) e na parte inferior da calandra se fez necessário uma serpentina 3/8" para coleta de 
condensado ligada em duas extremidades opostas, onde por uma única saída é coletado o condensado Figura 8.

Para conectar a mangueira de alta pressão, utilizou-se uma curva de 1" de encaixe com tubo de 1"no interior da calandra por onde se faz a entrada de vapor (essencial para aquecer o caldo no interior dos tubos de cobre) e como suporte da peça usou 3 pés de tubo $1 / 4 "$ e $650 \mathrm{~mm}$ de altura.

A parte superior do flange, corresponde a um tubo de aço inox 304 de 6" Figura 6 com redução de 6" para 1"/ 1/4", para observar instalou um visor de 1/2", uma curva de $1 " / 1 / 4$ " e o registro de 1"/1/4" para regular a saída de vapor.

O funil corresponde ao tubo (reservatório de caldo de cana) de 4" com redução 4" para $1 / 2 "$, onde adicionou-se um registro de $1 / 2^{\prime \prime}$ para regular a saída de caldo, junto ao tubo de 1/2" com 780mm de altura Figura 10.

Para comportar o condensado utilizou-se um balde de alumínio, já para realizar a coleta do caldo concentrado usou-se um coletor de brix e para medir a sua concentração o sacarímetro. O projeto por completo tem $1630 \mathrm{~mm}$ de altura e pesa aproximadamente $30 \mathrm{~kg}$ Figura 11 e Anexo 1. 
Figura 4: Tubos de cobre utilizados.

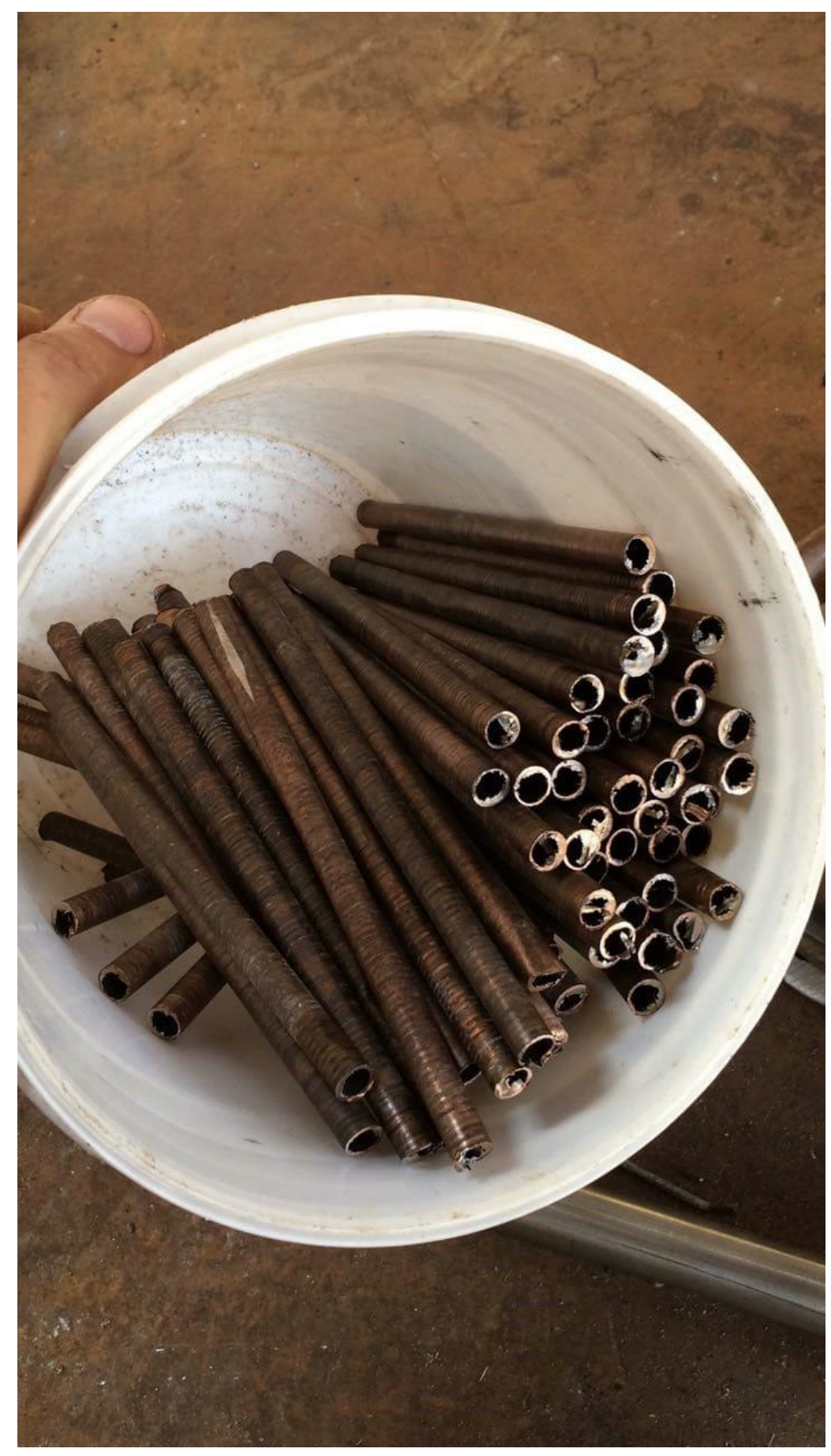

Fonte: autor.

Disponível em: https://www.nucleodoconhecimento.com.br/engenharia-quimica/evaporadormodelo-robert 
Figura 5: Modelo de espelho utilizado.

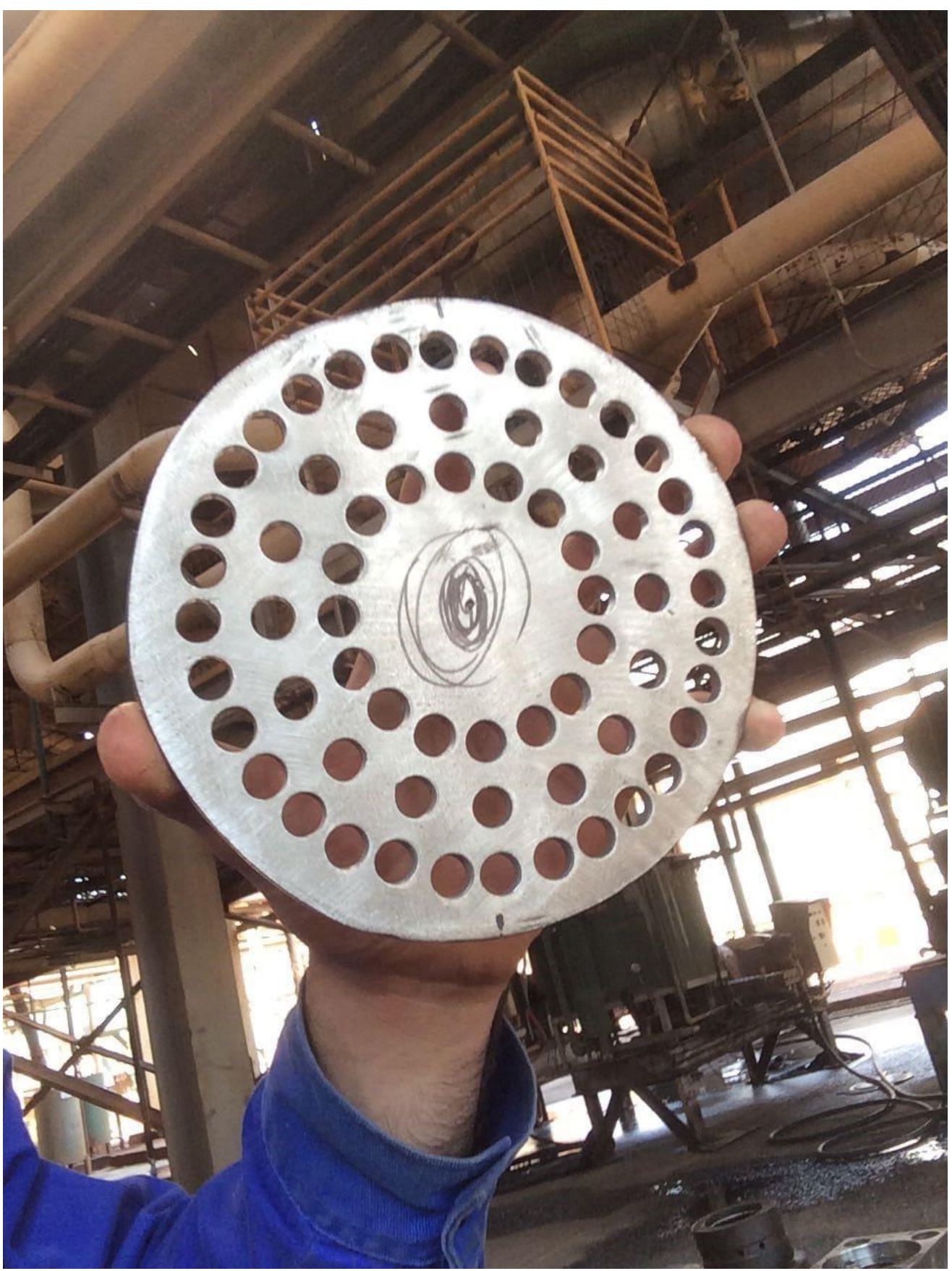

Fonte: autor.

Disponível em: https://www.nucleodoconhecimento.com.br/engenharia-quimica/evaporadormodelo-robert 
Figura 6: Chapa de aço carbono, parte superior do flange pré-montada e outras.

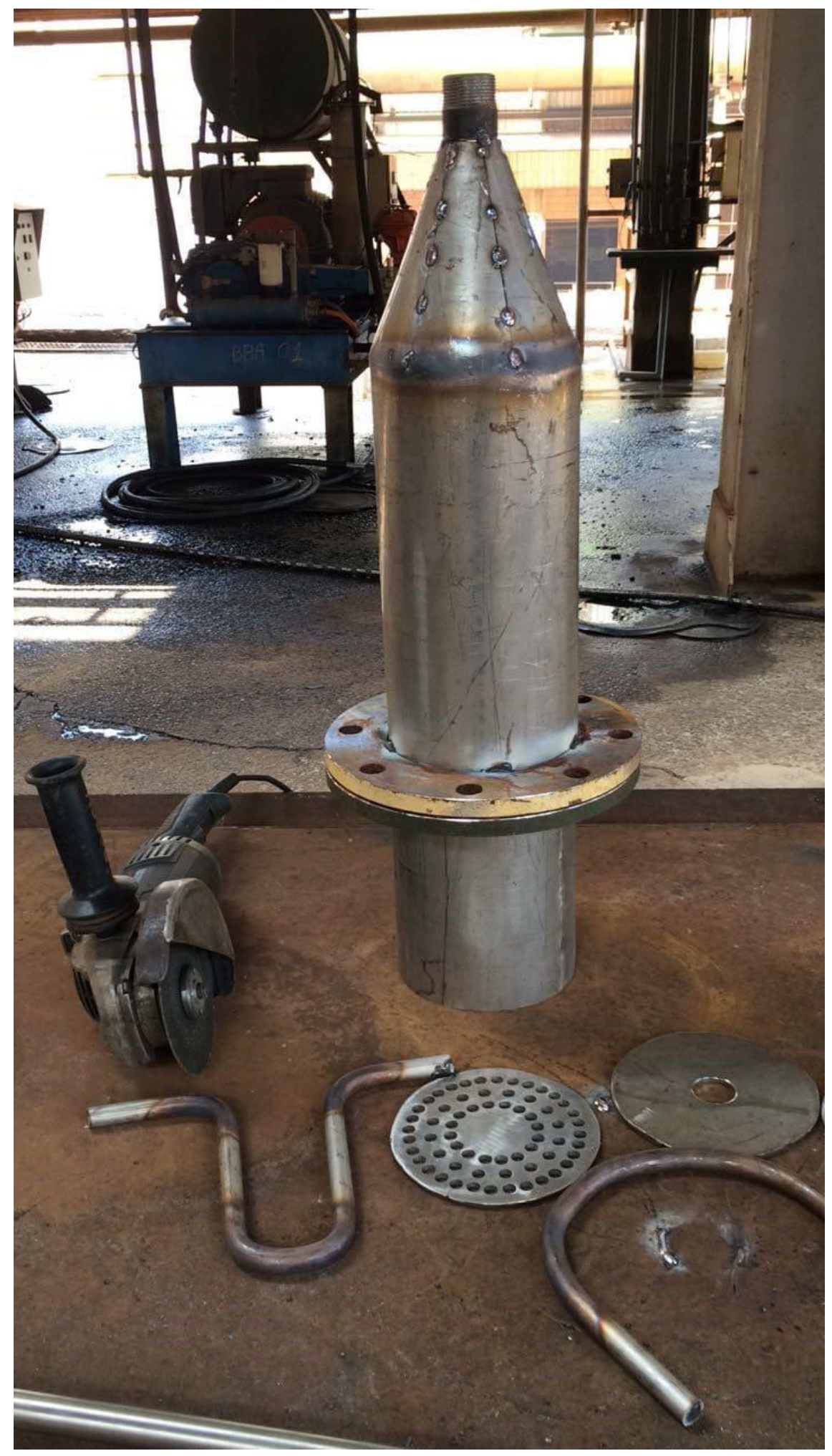

Fonte: autor.

RC: 31674

Disponível em: https://www.nucleodoconhecimento.com.br/engenharia-quimica/evaporadormodelo-robert 
Figura 7: Tubo de entrada de vapor.

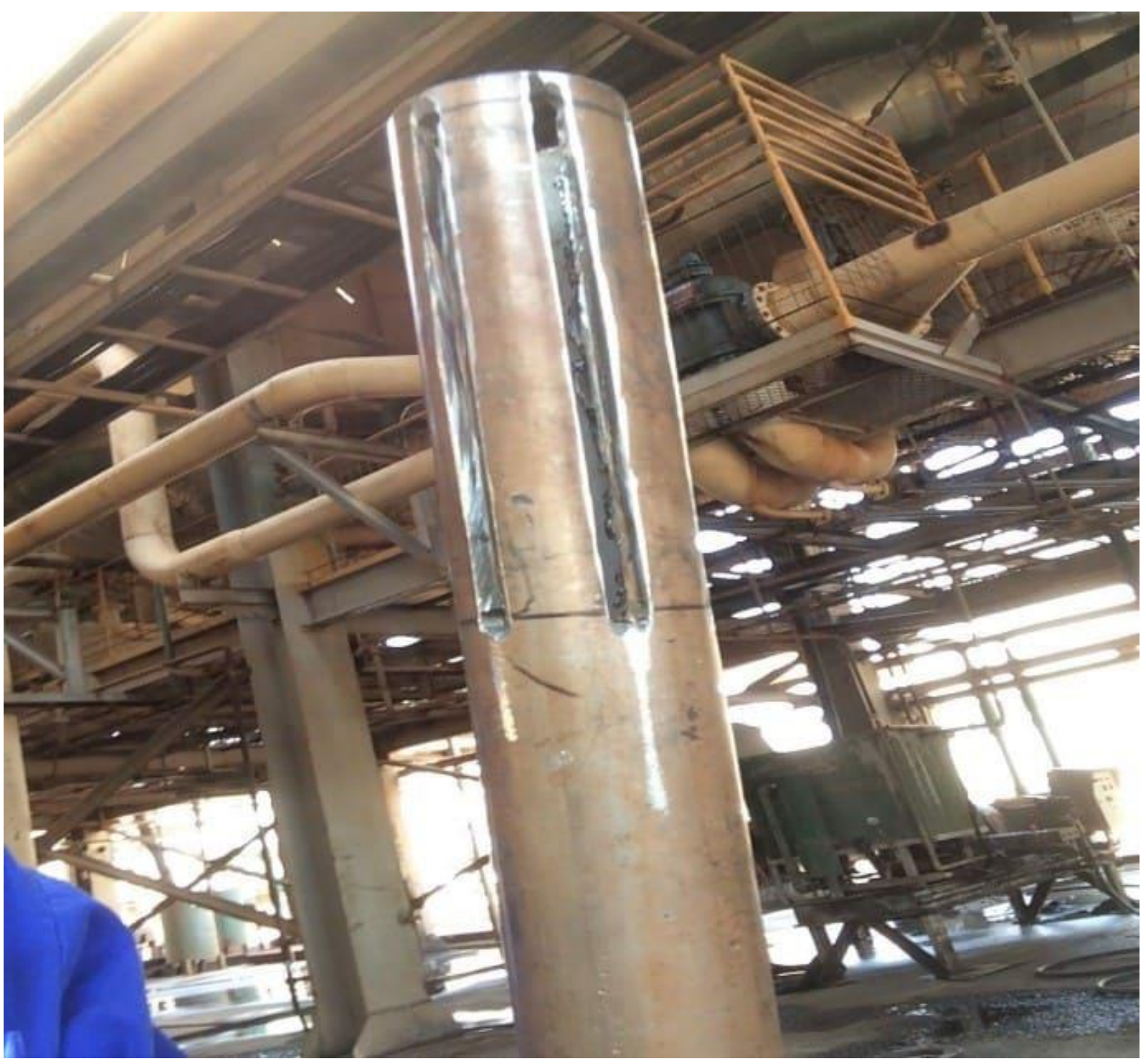

Fonte: autor.

Disponível em: https://www.nucleodoconhecimento.com.br/engenharia-quimica/evaporadormodelo-robert 
Figura 8: Parte inferior do flange, corresponde a calandra.

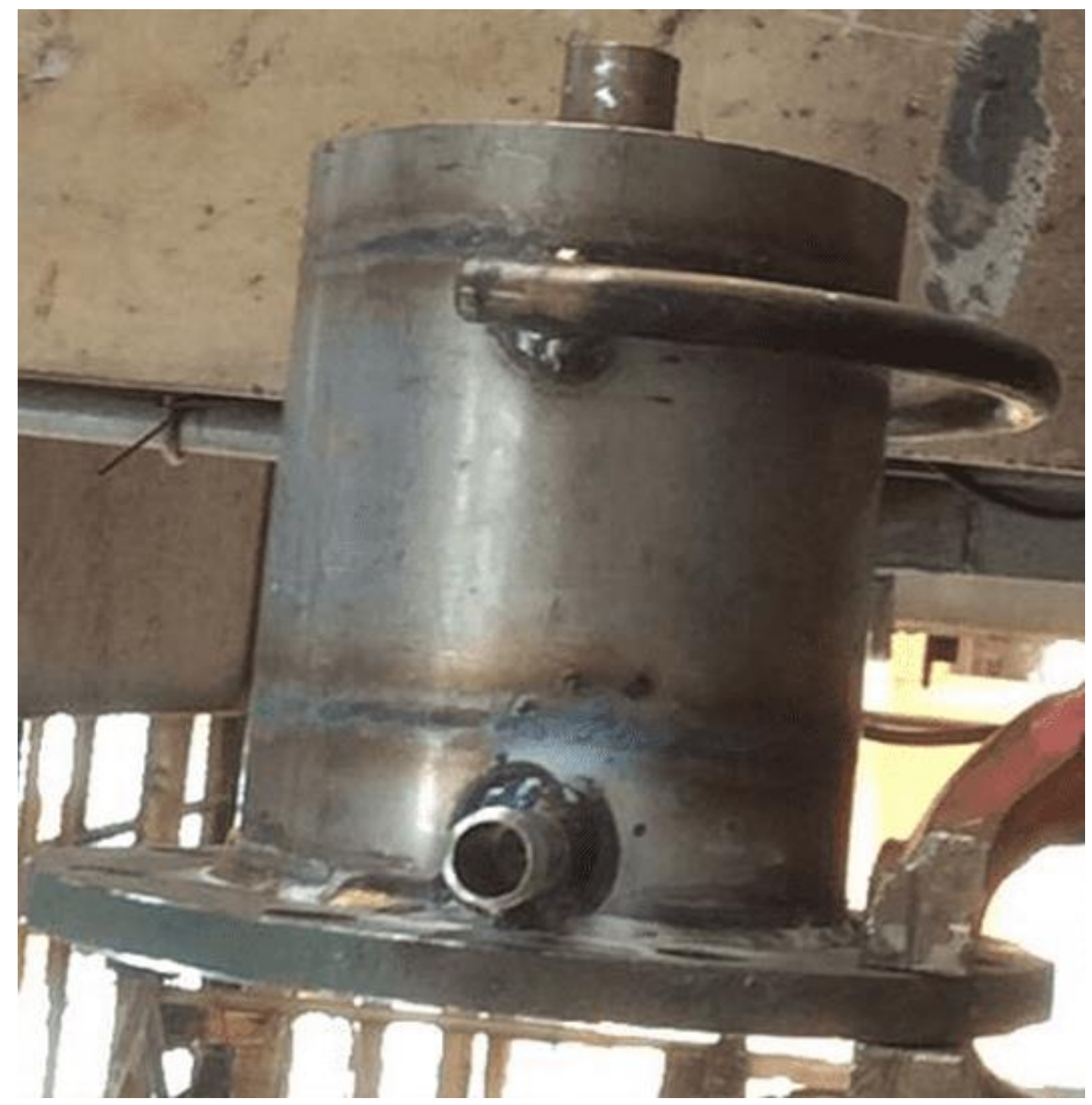

Fonte: autor.

Disponível em: https://www.nucleodoconhecimento.com.br/engenharia-quimica/evaporadormodelo-robert 
Figura 9: Demonstração interna da calandra.

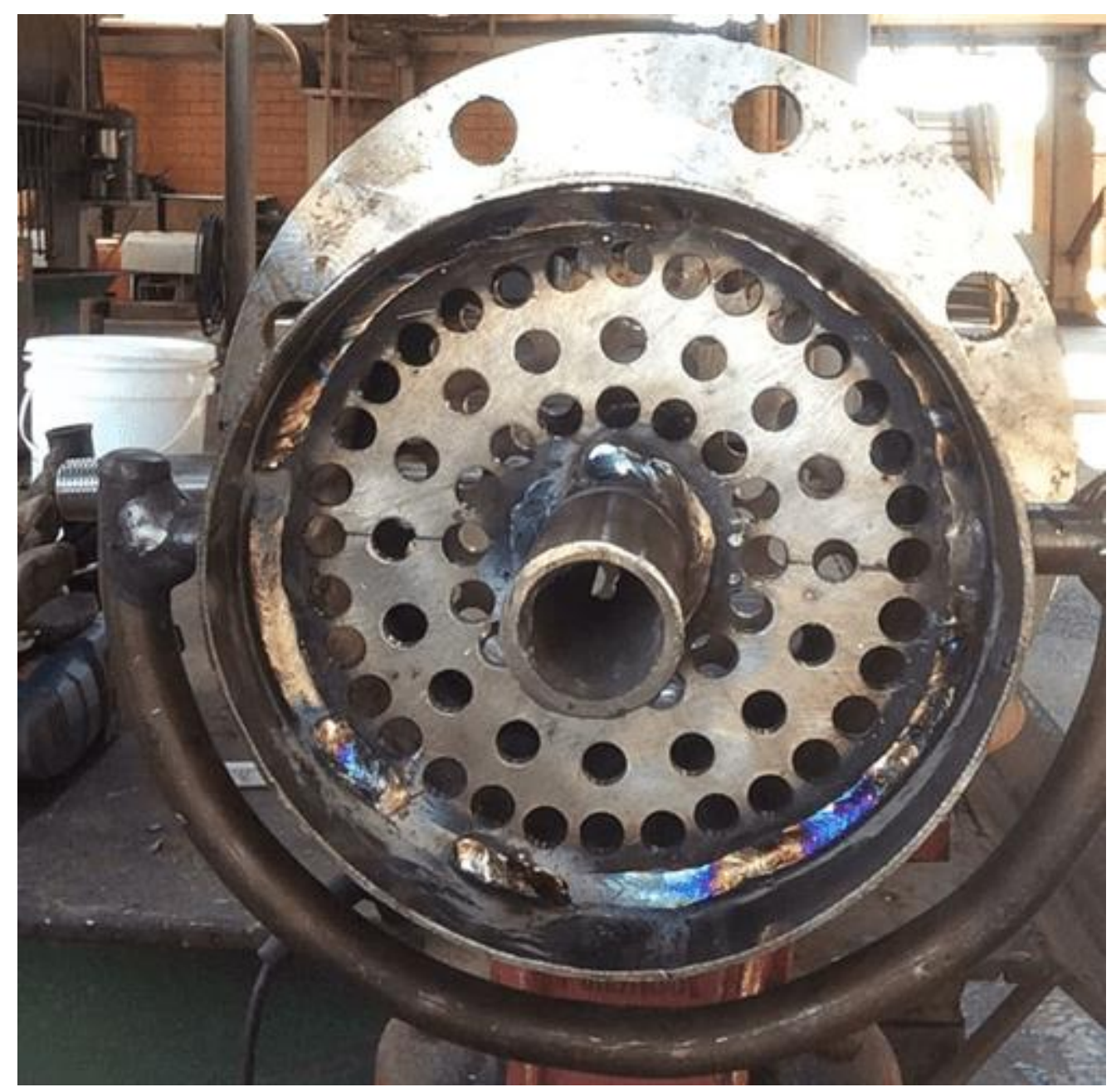

Fonte: autor.

Disponível em: https://www.nucleodoconhecimento.com.br/engenharia-quimica/evaporadormodelo-robert 
Figura 10: Evaporador final.

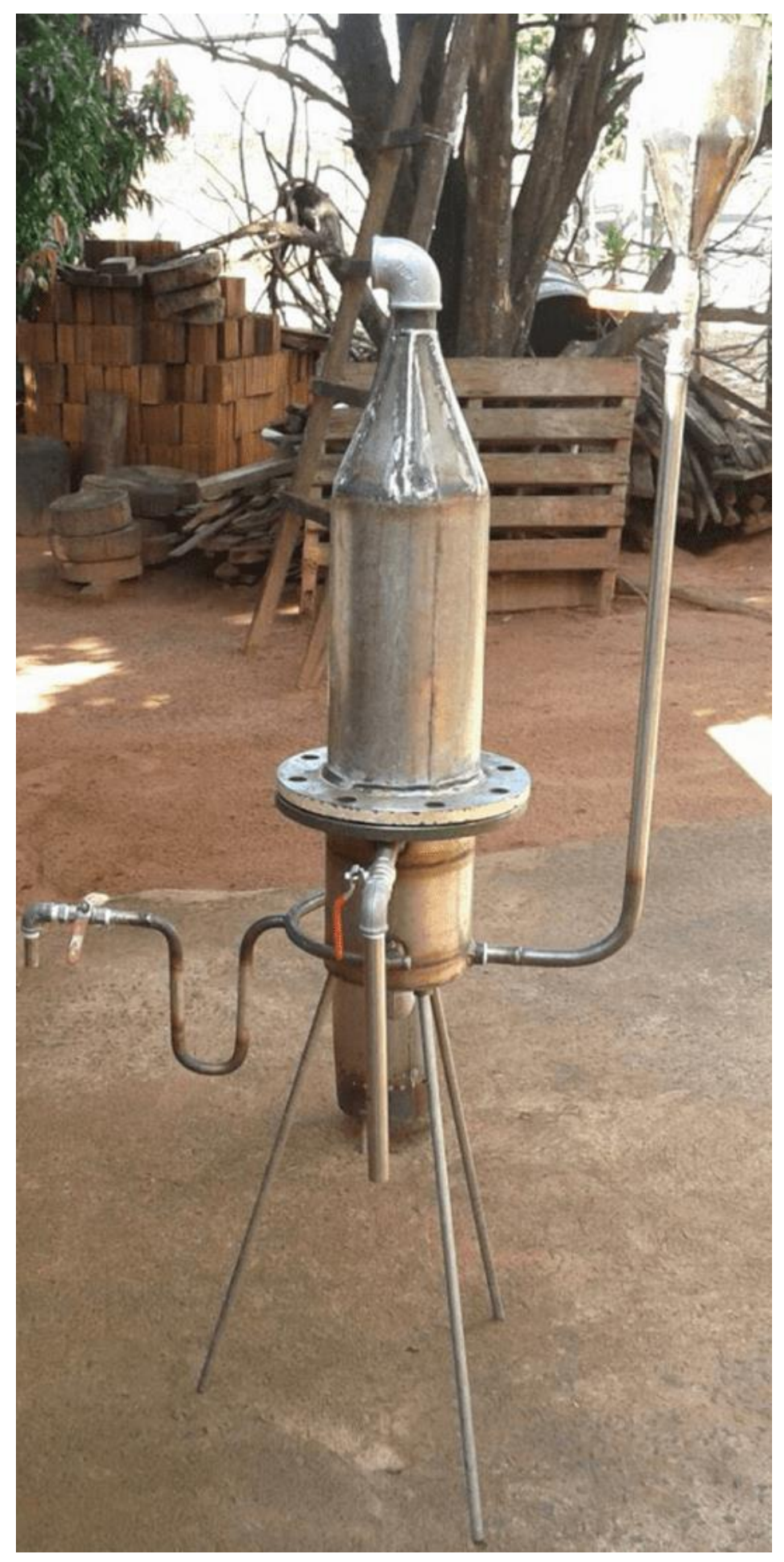

Fonte: autor.

RC: 31674

Disponível em: https://www.nucleodoconhecimento.com.br/engenharia-quimica/evaporadormodelo-robert 
Figura 11: Demonstração completa do sistema em funcionamento.

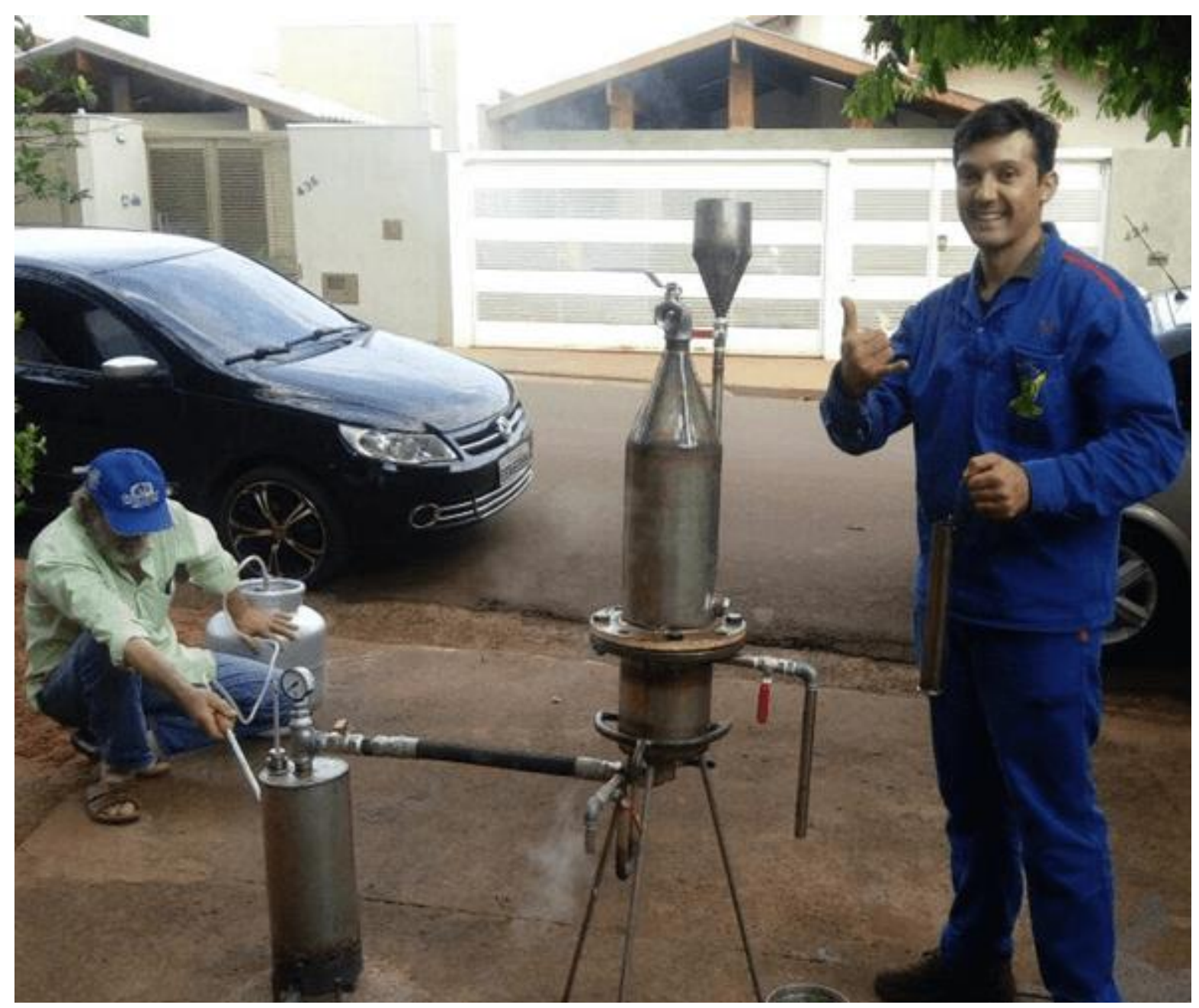

Fonte: autor.

\section{RESULTADOS EXPERIMENTAIS}

No dia 3 de novembro às $16 \mathrm{~h}$ foi realizado o $1^{\circ}$ teste. Foi observado vazamentos na mandrilhação (expansão dos tubos) do evaporador, que veio a vazar o condensado junto ao caldo, em vez de sair pela purga da calandra. Observou-se também que houve a diminuição do brix, em vez de elevá-lo.

No dia 5 de novembro às $17 \mathrm{~h}$ foi realizado o $2^{\circ}$ teste. Foram adicionados 3 litros de água na caldeira e aquecido a mesma com lança chama a fim de transformar a água em vapor, com $117^{\circ} \mathrm{C}$ e uma pressão de 200 a $500 \mathrm{~kg} / \mathrm{cm}^{2}$. Foi adicionado quatro litros

Disponível em: https://www.nucleodoconhecimento.com.br/engenharia-quimica/evaporadormodelo-robert 
de caldo de cana a $90^{\circ} \mathrm{C}$ na entrada do evaporador, vindo a encher o corpo do evaporador e assim trocando calor na calandra, resultando assim a evaporar a água contida no caldo. O caldo entrou com o brix de $7 \%$ e saindo com brix de $14 \%$.

Com os dados obtidos no segundo teste foi possível calcular a área, vazão de entrada, vazão de saída de caldo e taxa de evaporação, de acordo com os cálculos:

Cálculo para a área da calandra (troca térmica): $A=\pi . \emptyset . h$. quantidadedetubos $A=\pi$. (7,52x10-3).0,12.64 $A=0,18 m^{2}$.

Para a vazão de entrada de caldo consideramos uma velocidade de $1,8 \mathrm{~ms} / \mathrm{com}$ diâmetro $(\varnothing)$ de $12,5 \mathrm{~mm}$ obtendo a vazão de $0,7 \mathrm{~m} 3 \mathrm{p} /$ entrada do caldo. Já para a vazão de saída de caldo utilizamos a seguinte equação: $Q s=Q e .(1-B e B x)$

Onde:

Qe:vazãodeentradadecaldoBe:brixdoclarificadoBx:brixdoxaropeQs:vazãodesaídad ecaldo

$Q s=0,7 .(1-714)=>Q s=0,35 \mathrm{~m} 3 / \mathrm{h}$

Tendo a taxa de evaporação sendo:

$\%=Q s Q e .100=>\%=0,350,7.100=>\%=50 \%$ taxadeevaporação.

\section{CONCLUSÃO}

Conforme a metodologia adotada para a confecção do projeto evaporador modelo Robert, se fez necessário avaliar os resultados obtidos na fase de testes, sendo possível avaliar em primeira instancia seu funcionamento, como fator primordial para que todo o processo se corresponde ao modelo proposto.

Desta maneira, pode-se dar sequência a outros critérios avaliativos, como a vazão de entrada e saída de caldo, teor de brix atingido e taxa de evaporação, tendo em vista 
que o projeto se baseia em um evaporador industrial utilizado na usina colombo para a fabricação de açúcar.

Assim pode-se concretizar com base nos cálculos que o projeto corresponde a $2 \%$ da modelo base. Portanto pode-se concluir que os objetivos propostos foram concretizados com êxito.

\section{REFERÊNCIAS}

ARAUJO, E. C. DA C. EVAPORADORES. SÃO CARLOS: EDUFSCAR, 2012. (APONTAMENTOS).

EVAPORAÇÃO. EVAPORADORES DE MÚLTIPLOS EFEITOS. 2015.DISPONÍVELEM:<http://web.ist.utl.pt/ist10738/extdoc/eps/Exemplo104.pdf>.ACESSO EM: 29 NOV. 2015.

FOUST, A; S.; WENZEL, L. A.; CLUMP, C. W.; MAUS, L.; ANDERSEN, L. B. PRNCÍPIOS DAS OPERAÇÕES UNITÁRIAS. 2. ed. Rio de Janeiro: LTC, 1982.

MCCABE, W. L.; SMITH, J. C.; HARRIOT, P. OPERACIONES UNITARIAS EN INGENIERIA QUIMICA. 4. ED. MADRID: MCGRAW-HILL, 1991. 1095 P. MILCENT, P. F. OPERAÇÕES UNITÁRIAS II. EVAPORAÇÃO. UNIVERSIDADE FEDERAL DO PARANÁ, 2013.

ROGÉRIO, H. A., COSTA, A.O.S, JÚNIOR COSTA, E.F., "APLICAÇÕES INDUSTRIAIS DE EVAPORADORES DE MÚLTIPLOS EFEITOS”, CENTRO CIENTÍFICO CONHECER, (16), 28152834(2013).

WALAS, S, M. CHEMICAL PROCESS EQUIPMENT: SELECTION AND DESIGN. KANSAS: BUTTERWORTH-HEINEMANN, 1990. 755 P.

Enviado: Abril, 2019.

Aprovado: Junho, 2019. 